\title{
Field trials of the Baby Check score card: mothers scoring their babies at home
}

\author{
A J Thornton, C J Morley, S J Green, T J Cole, K A Walker, J M Bonnett
}

\begin{abstract}
The Baby Check score card has been developed to help parents and health professionals grade the severity of acute illness in babies. This paper reports the results of two field trials in which mothers used Baby Check at home, 104 mothers scoring their babies daily for a week and 56 using it for six months. They all found Baby Check easy to use, between $68 \%$ and $81 \%$ found it useful, and $96 \%$ would recommended it to others. Over $70 \%$ of those using it daily used it very competently. Those using it infrequently did less well, suggesting that familiarity with the assessment is important. The scores obtained show that Baby Check's use would not increase the number of mothers seeking medical advice. With introduction and practice most mothers should be able to use Baby Check effectively. It should help them assess their babies' illnesses and make appropriate decisions about seeking medical advice.
\end{abstract}

Parents recognise when their baby is unwell, but they may have difficulty assessing the severity of the illness and deciding on appropriate management. ${ }^{1-3}$ 'Baby books' describe specific diseases, but do not help parents assess illness severity. Advice about when to call a doctor is often vague.

Baby Check is a score card developed to help parents and health professionals grade the severity of acute illness in babies under 6 months old. ${ }^{45}$ It contains 19 simple checks (seven symptoms and 12 signs), each carrying a score. The scores for positive checks are added together. The higher the total score, the sicker the baby.

The 19 checks as described for professionals are summarised in a companion paper. ${ }^{4}$ For parents, an illustrated booklet has been developed. Each check is explained in simple

University of Cambridge, Department of Paediatrics

A J Thornton

C J Morley

$S$ J Green

K A Walker

J M Bonnett

MRC Dunn Nutrition

Unit, Cambridge T J Cole

Correspondence to:

Dr C J Morley,

University of Cambridge,

University of Cambridge, Levartment of Paediatrics, Lovel E8, Addenbrooke's Cambridge CB2 2OQ

Accepted 10 August 1990 use it competently, and react appropriately to its guidance. The scores mothers obtain should be reliable when compared with those of a trained observer, and accurately reflect illness severity. General practitioners need reassurance that well babies do not obtain falsely high scores.

This paper reports the results of two field trials in which mothers used Baby Check at home.

\section{Subjects and methods}

STUDY A: MOTHERS SCORING BABIES AT HOME DAILY FOR ONE WEEK

The study involved 104 mothers of term babies, randomly selected from the birth register. They were approached postnatally and asked to score their babies daily for a preallocated week and to record contacts with their doctor, health visitor, or midwife. Babies were assessed uniformly across the first six months of life.

The mothers received no instructions other than those in Baby Check, which was posted to them shortly before they started scoring. They were told it was a research project and that they should not rely on it when deciding whether to contact a doctor. At the end of the week a research nurse visited, watched the mother score her baby, graded her competence in using Baby Check, questioned her about it, and then scored the baby herself.

Of the 104 participants, $72(69 \%)$ were the original mothers approached and $32(31 \%)$ were substitutes for mothers who refused.

STUDY B: MOTHERS USING BABY CHECK AT HOME FOR SIX MONTHS

Seventy mothers of term babies born on selected days were invited to take Baby Check home to use whenever they wished, until their baby was 6 months old. They were given no additional instructions in its use. They were advised that it was a research project. A research nurse visited when the babies were 8 (visit 1) and 16 weeks' old (visit 2). The procedure for each visit and for recording medical contacts was as in study A. The mothers received a questionnaire about Baby Check at the end of six months.

Sixty seven $(96 \%)$ of the mothers approached agreed to participate, but 11 subsequently withdrew. Fifty five were seen at each visit, but one did not score her baby at visit 2 . Fifty (89\%) of the 56 questionnaires were returned.

Table 2 shows the mothers' social class and educational qualifications.

Statistical analyses were performed with SPSSX, using correlations, paired and unpaired $t$ tests. 
Unusual cry

You will be used to your baby's normal cries (from hunger, tiredness, etc). An unusual cry is different.

It may be weak, hoarse, high pitched or painful for example.

If your baby's cries have been normal in the last 24 hours:

Score 0

If your baby has been crying in an unusual way in the last 24 hours:

Score 2

Score for one box only.

Figure 1 Examples of how the checks are described.

Table 1 Summary of advice given to parents for each score group

\begin{tabular}{ll}
\hline Score & Advice \\
\hline 0 to 7 & $\begin{array}{c}\text { Your baby is well or only a little unwell and is } \\
\text { not likely to need medical attention at the } \\
\text { moment } \\
\text { Your baby is unwell but is not likely to be } \\
\text { seriously ill at the moment. Contact your } \\
\text { doctor, health visitor, or midwife for advice. } \\
\text { Watch your baby closely. If you think your } \\
\text { baby is getting worse, do the score again } \\
\text { Your baby is ill and needs to be seen by a doctor. } \\
\text { Contact your doctor now and arrange for your } \\
\text { baby to be seen }\end{array}$ to $19 \quad \begin{array}{c}\text { Your baby may be seriously ill and needs to be } \\
\text { seen by a doctor straight away }\end{array}$ \\
\hline
\end{tabular}

Results

THE NUMBER OF TIMES THE MOTHERS USED BABY CHECK

In study $A, 701(96 \%)$ of 728 possible daily scores were completed.

In study B, 33 mothers (59\%) used Baby Check spontaneously between visits, 13 (23\%) once, eight (14\%) two to four times, and 12 $(22 \%)$ five times or more.

\section{MOTHERS' IMPRESSIONS OF BABY CHECK \\ Ease of use}

All the mothers rated Baby Check as easy to use in study A. In study B all but two (4\%) thought it easy at visit 1 . All thought it easy at visit 2 .

\section{Difficult checks}

Most mothers did not find any checks difficult. Thirty six (35\%) mentioned difficulties in study $A, 21(38 \%)$ in study $B$ at visit 1 , and seven $(13 \%)$ at visit 2 . In study $B$ the better educated mothers were the most likely to report checks as difficult $(r=0.52, p<0.001)$. Only recession, rectal temperature, fluid intake, hernia, and circulation were mentioned by more than three (table 3).

Recession accounted for 41 (43\%) of the reports. Mothers were unsure what to look for. When shown a photograph of recession at visit $2,34(62 \%)$ said they would recognise it from Baby Check's description.

Baby Check requires mothers to take their baby's rectal temperature using the digital

\section{Circulation}

This check is about how well your baby's blood is circulating to the fingers and toes.

Squeeze your baby's big toe firmly for two seconds,

to make a white patch.

(To time two seconds count: 'One squeeze the toe,

two squeeze the toe'). Then let go and count three seconds.

Watch how quickly the colour returns.

If your baby's toe returns to its norma

colour within three seconds:

Score 0

If your baby's toe does not return to its normal colour within three seconds, or was completely white to start with:

Score 3

Score for one box only.

Table 2 Mothers' social class and educational qualifications. Results are number (\%)

\begin{tabular}{lrr}
\hline & $\begin{array}{c}\text { Study } A \\
(n=104)\end{array}$ & $\begin{array}{l}\text { Study } B \\
(n=56)\end{array}$ \\
\hline Social class: & $27(26)$ & $8(14)$ \\
I & $21(20)$ & $13(23)$ \\
II & $4(4)$ & $-21(38)$ \\
III Non-manual & $34(33)$ & $3(5)$ \\
III Manual & $8(8)$ & $5(9)$ \\
IV & $5(5)$ & $6(11)$ \\
V & $4(4)$ & - \\
Other & $1(1)$ & - \\
Not coded & $15(14)$ & $10(18)$ \\
Mother's educational qualifications: & $11(11)$ & $9(16)$ \\
No qualifications & $36(35)$ & $17(30)$ \\
54 CSEs/hairdressing/typing & $12(12)$ & $4(7)$ \\
>4 CSEs/any O levels & $24(23)$ & $16(29)$ \\
A levels/vocational training & $6(6)$ & - \\
Degree/professional qualification &
\end{tabular}

Table 3 Checks reported as difficult. Results are number (\%)

\begin{tabular}{|c|c|c|c|}
\hline \multirow[t]{2}{*}{ Check } & \multirow{2}{*}{$\begin{array}{l}\text { Study A } \\
(n=104)\end{array}$} & \multicolumn{2}{|l|}{ Study B } \\
\hline & & $\begin{array}{l}\text { Visit 1 } \\
(n=55)\end{array}$ & $\begin{array}{l}\text { Visit 2 } \\
(n=54)\end{array}$ \\
\hline $\begin{array}{l}\text { Recession } \\
\text { Rectal temperature } \\
\text { Reduced fluids } \\
\text { Hernia } \\
\text { Circulation }\end{array}$ & $\begin{array}{rr}25 & (24) \\
7 & (7) \\
5 & (5) \\
3 & (3) \\
3 & (3)\end{array}$ & $\begin{array}{ll}11 & (20) \\
3 & (5) \\
3 & (5) \\
4 & (7) \\
3 & (5)\end{array}$ & $\begin{array}{ll}3 & (6) \\
1 & (2) \\
1 & (2) \\
1 & (2)\end{array}$ \\
\hline
\end{tabular}

Recession was also reported twice on the final questionnaire (study B).

The remaining checks were reported as difficult on three occasions or less.

thermometer provided. Ten (6\%) mothers thought this was difficult, five of whom had not attempted it. Of those who took the temperature, only five (5\%) in study $A$, and none in study B thought it difficult.

Those mothers who found fluid intake difficult to quantify were breast feeding. Those who mentioned hernia were unsure what to look for and with circulation (fig 1) they were unsure about detecting the colour change.

\section{Disliked checks}

Rectal temperature was disliked by 41 mothers (39\%) in study A. In study $\mathbf{B}$, the number dropped from $22(40 \%)$ at visit 1 to $10(19 \%)$ at visit 2. Reasons included fear of hurting the baby and feeling the check was unnecessary. Most mothers were willing to do the check. In study $A, 91(88 \%)$ took the temperature at least once. In study B at visit $1,36(67 \%)$ did the 
check (about half requiring persuasion) and 18 $(33 \%)$ refused. At visit 2 , only $10(19 \%)$ refused and fewer needed persuasion.

The circulation check was disliked by two mothers $(2 \%)$ in study A. Both were afraid of hurting the baby.

\section{Does Baby Check cause anxiety or provide reassurance?}

The mothers in study A were asked whether Baby Check caused anxiety or provided reassurance. Forty six $(46 \%)$ found it reassuring. Only four (4\%) said it caused anxiety.

\section{Usefulness}

In study A, 75 (74\%) mothers thought Baby Check was useful. In study B, $43(81 \%)$ at visit $1,41(76 \%)$ at visit 2 , and $43(68 \%)$ on the final questionnaire thought it useful. All thought other mothers would find it useful and 47 (96\%) said they would recommend it.

Eighty four mothers (83\%) in study A said they would like a copy of Baby Check and 69 $(68 \%)$ said they would buy it. In study B (visit 2) the numbers were $45(87 \%)$ and $44(83 \%)$ respectively. First time mothers were slightly more likely to want a copy than those who had other children $(r=0 \cdot 27, p<0 \cdot 05)$. On the final questionnaire $38(76 \%)$ said they would like one if they had another baby. Forty $(80 \%)$ would buy it. On average they were willing to pay $£ 5 \cdot 75$.

\section{Willingness to trust Baby Check}

The mothers in study B were asked whether they would trust Baby Check to help them decide when to contact the doctor. At visit 2, 25 (46\%) said they would, 19 (34\%) would not, and $11(20 \%)$ were unsure. By the end of the study, $32(64 \%)$ said they would, though many said it would not override their own judgment.

MOTHERS' COMPETENCE IN USING BABY CHECK Table 4 shows the nurse's grading of the mothers' competence in using Baby Check.

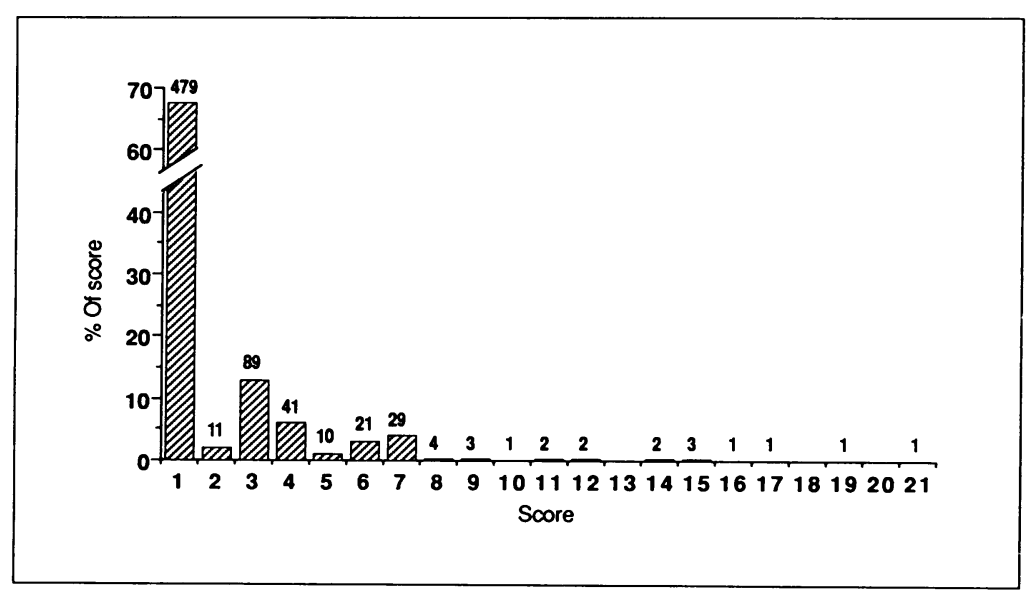

Figure 2 Profile of daily scores $(n=701)$. The number of babies with each score are shown at the top of each column.
Table 4 Mothers' competence in using Baby Check at the nurse's visit. Results are number (\%)

\begin{tabular}{|c|c|c|c|}
\hline \multirow{2}{*}{$\begin{array}{l}\text { Competence } \\
\text { grading }\end{array}$} & \multirow{2}{*}{$\begin{array}{l}\text { Study } A \\
(n=100)\end{array}$} & \multicolumn{2}{|l|}{ Study $B$} \\
\hline & & $\begin{array}{l}\text { Visit 1 } \\
(n=55)\end{array}$ & $\begin{array}{l}\text { Visit 2 } \\
(n=54)\end{array}$ \\
\hline $\begin{array}{l}\text { Excellent } \\
\text { Good } \\
\text { Reasonable } \\
\text { Dubious } \\
\text { Poor } \\
\text { Very poor } \\
\text { Not gradeed }\end{array}$ & $\begin{array}{rr}26 & (26) \\
45 & (45) \\
9 & (9) \\
5 & (5) \\
9 & (9) \\
1 & (1) \\
5 & (5)\end{array}$ & $\begin{array}{r}3(6) \\
15(27) \\
21(38) \\
9(16) \\
3(6) \\
4(7) \\
-\end{array}$ & $\begin{array}{r}6(11) \\
14(26) \\
17(31) \\
9(17) \\
4(7) \\
3(6) \\
1(2)\end{array}$ \\
\hline
\end{tabular}

Those whose competence was not graded scored their babies 'from memory', Four mothers in study $\mathrm{A}$, and one at visit 2 in study $\mathrm{B}$ did not do an assessment at the visit. The assessment was graded as reasonable or better for 80 mothers $(80 \%)$ in study $A, 39(71 \%)$ at visit 1 and 37 $(69 \%)$ at visit 2 in study $B$.

Four mothers (4\%) in study $A$ and two in study $B$ made arithmetical errors.

\section{Factors affecting mothers' competence}

In both studies, mothers' competence was weakly correlated to social class $(r=0 \cdot 24, p=0.01$ and $r=0.25, p<0.05$ ), mothers from the manual classes performing slightly less well.

In study B, mothers who had used Baby Check beforehand performed significantly better at visit 1 than those who had not $(r=0.5$, $\mathrm{p}<0.001)$. This effect was absent at visit 2 . Mothers with no qualifications (table 2) performed better assessments at visit 1 than those with fewer than four passes at the certificate of secondary education (CSE) $(p<0.05)$. Those with fewer than four CSEs performed significantly less well than the graduate mothers $(\mathrm{p}=<0.05)$.

The mothers' age and parity had no significant effect on their competence in using the score card in either study.

\section{PROFILE OF SCORES}

Figure 2 shows the profile of daily scores in study A. Of 95 babies with all seven daily scores, $84(88 \%)$ scored less than 8 every day.

Table 5 shows all the mothers' scores, in the four score groups. The scores done between visits in study B were higher than those done routinely in either study.

\section{AGREEMENT BETWEEN THE MOTHERS' AND NURSE'S SCORES}

In study B, four assessments from each visit were excluded because the scores recorded by the mother were uninterpretable.

There was no significant difference between the distribution of the mothers' and nurse's total scores. They were identical in $77(77 \%)$ cases in study $\mathrm{A}$, in $32(63 \%)$ at visit 1 , and in 38 $(76 \%)$ at visit 2 . The mean (SD) difference between the scores was $-0 \cdot 2(1 \cdot 6)$ in study $A$, $0.5(2.5)$ at visit 1 , and $-0.1(2 \cdot 7)$ at visit 2 . Sixteen mothers $(16 \%)$ in study $A, 12(24 \%)$ at visit 1 and five $(10 \%)$ at visit 2 scored lower than the nurse, while seven (7\%) in study $A$, and seven 
Table 5 Distribution of mothers' scores. Results are number (\%)

\begin{tabular}{|c|c|c|c|c|c|}
\hline \multirow[t]{2}{*}{ Score } & \multicolumn{2}{|l|}{ Study $A$} & \multicolumn{3}{|l|}{ Study B } \\
\hline & $\begin{array}{l}\text { Daily } \\
(n=701)\end{array}$ & $\begin{array}{l}\text { Visit } \\
(n=100)\end{array}$ & $\begin{array}{l}\text { Visit 1 } \\
(n=51)\end{array}$ & $\begin{array}{l}\text { Visit 2 } \\
(n=50)\end{array}$ & $\begin{array}{l}\text { Between visits } \\
(n=117)\end{array}$ \\
\hline $\begin{array}{l}0 \text { to } 7 \\
8 \text { to } 12 \\
13 \text { to } 19 \\
20 \text { or more }\end{array}$ & $\begin{array}{r}680(97) \\
12(2) \\
8(1) \\
1(<1)\end{array}$ & $\begin{array}{l}97(97) \\
3 \quad(3) \\
-\end{array}$ & $\begin{array}{r}49(96) \\
1 \quad(2) \\
1 \quad(2) \\
-\end{array}$ & $\begin{array}{r}48(96) \\
1(2) \\
1 \quad(2) \\
-\end{array}$ & $\begin{array}{rr}97 & (83) \\
10 & (9) \\
8 & (7) \\
2 & (2)\end{array}$ \\
\hline
\end{tabular}

Table 6 Checks scored differently by the mother and nurse, showing whether the mother scored higher or lower than the nurse. Results are number (\%)

\begin{tabular}{|c|c|c|c|c|c|c|}
\hline \multirow[t]{3}{*}{ Check } & \multirow{2}{*}{\multicolumn{2}{|c|}{$\begin{array}{c}\text { Study } A \\
(n=100)\end{array}$}} & \multicolumn{4}{|l|}{ Study B } \\
\hline & & & \multicolumn{2}{|c|}{ Visit $1(n=51)$} & \multicolumn{2}{|c|}{ Visit $2(n=50)$} \\
\hline & $\begin{array}{l}\text { Mother } \\
\text { high }\end{array}$ & $\begin{array}{l}\text { Mother } \\
\text { low }\end{array}$ & $\begin{array}{l}\text { Mother } \\
\text { high }\end{array}$ & $\begin{array}{l}\text { Mother } \\
\text { low }\end{array}$ & $\begin{array}{l}\text { Mother } \\
\text { high }\end{array}$ & $\begin{array}{l}\text { Mother } \\
\text { low }\end{array}$ \\
\hline $\begin{array}{l}\text { Crying } \\
\text { Circulation } \\
\text { Recession } \\
\text { Rash } \\
\text { Cyanosis } \\
\text { Reduced fluids }\end{array}$ & $\begin{array}{l}1(1) \\
2(2) \\
1(1) \\
-2(2) \\
-\end{array}$ & $\begin{array}{l}9(9) \\
7(7) \\
1(1) \\
2(2) \\
- \\
-\end{array}$ & 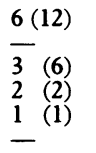 & $\begin{array}{ll}5 & (10) \\
2 & (4) \\
2 & (4) \\
-1 & (1) \\
1 & (2)\end{array}$ & $\begin{array}{l}\overline{1(2)} \\
- \\
\overline{2} \\
2(4)\end{array}$ & $\begin{array}{l}- \\
3(6) \\
3(6) \\
1(2) \\
-1(2)\end{array}$ \\
\hline
\end{tabular}

The remaining checks were scored differently on three occasions or less.

(14\%) at each visit in study B scored higher. The mothers' and nurse's scores fell into different scoring groups in only three cases.

The agreement in scoring of individual checks was between $78 \%$ and $100 \%$. The checks which gave rise to most differences are shown in table 6 . The differences in the scoring of crying often arose when babies who were content when their mothers assessed them, cried during the nurse's examination. Doing the circulation check, some mothers did not squeeze the toe firmly enough. In seven cases (70\%) with differences in the scoring of recession, and in three $(60 \%)$ where rash was scored differently, the mother did not undress or examine the baby.

MEDICAL CONTACTS

In study $\mathrm{A}, 10$ babies $(10 \%)$ had 18 contacts with their health visitor, midwife, or doctor, mostly for minor complaints. Six mothers reported that Baby Check had helped them decide whether or not to seek advice; four were reassured by a low score, and scores of 15 and 19 prompted two to seek advice-one baby had a chest infection, the other asthma and a severe cold.

In study B, 53 contacts were recorded. There were also 79 unrecorded contacts reported at the visits. The scores completed between visits were correlated with the recorded contacts. Twenty two (42\%) had a score done the same day. A contact was recorded for seven $(70 \%)$ of 10 scores of 13 or more compared with only seven $(7 \%)$ of 97 scores below 8 .

\section{Discussion}

The mothers found Baby Check easy to use, the majority found it useful, and almost all would recommend it to others. Most would like a copy and would be prepared to buy it.

Overall $75 \%$ of the mothers used Baby Check at least reasonably well. It study $\mathrm{A}, 71 \%$ used it very competently. In study B they performed less well. Initially more mothers found checks difficult in study B and there was greater disagreement between the mothers' and nurse's scores, but as the study progressed they reported fewer difficulties, the agreement improved and they became more inclined to trust Baby Check and to consider it useful. Familiarity with the assessment is thus important. The booklet is currently being revised, encouraging mothers to practise by scoring their well babies, and to ask their health visitor or midwife about checks that need clarifying. The text and illustrations for the checks causing most difficulty are being improved.

For those mothers who are unable to use Baby Check reliably, it would be possible to devise a simpler check list, based on a few individual symptoms. However such a system would inevitably be much less sensitive and specific. It could thus cause increased anxiety and cause ill babies to be missed.

The mothers' willingness to use and trust Baby Check will have been influenced by its presentation as a research project rather than as a decision aid. They were given no help in its use, whereas in future they could be introduced to it by their health visitor, midwife, or by a video. This should further increase their competence.

The mothers were asked to score well babies. They would usually use Baby Check when the baby was unwell. This may have affected their motivation to complete the assessments properly and to take the rectal temperature. It may also have increased their uncertainty about some checks-many thought they would recognise signs such as recession if present.

The sample was biased towards the higher social classes and professional mothers, but just under half were from manual classes and a third had fewer than four CSEs. The analyses suggest that social class and education have only a marginal effect on mothers' reactions to and competence with Baby Check.

Although not common in this country, mothers take their baby's rectal temperature routinely in Europe. The Baby Check thermometer has a collar to prevent its being inserted too far into the rectum. Most mothers were willing to take the temperature and did so competently. The number who disliked it or thought it difficult fell once they had tried it. The mothers were asked to undertake a new procedure on a well baby without teaching. Their only guidance was that contained in Baby Check. In future health visitors or midwives could show mothers how to take the rectal temperature.

Clinicians assessing signs agree only about $68 \%$ of the time. ${ }^{6}$ The agreement between the mothers' and nurse's scores was good, provided the mother undressed and examined the baby. Some differences in scoring arose because they did not, and the instructions have since been improved. Differences in the scoring of crying usually reflected the baby's true state. The advice given by Baby Check depends on the scoring group-there were only three cases 
where the mother's and nurse's scores fell into different groups.

Because there were few ill babies conclusions cannot be drawn about mothers' ability to recognise signs and symptoms when present, but it is important to establish that the mothers do not overscore. When the score was applied to 298 babies seen at home in the original study, ${ }^{45}$ $289(97 \%)$ scored 0 to 7 , six (2\%) scored 8 to 12 , and three (1\%) scored 13 to 19 . The profile of scores in these studies is very similar, confirming that well babies assessed by their mothers score low.

Only 11 babies (12\%) in study A scored 8 or more during the week. This is fewer than the number who contact their doctor at the moment. ${ }^{7}$ Thus if mothers were to use Baby Check, fewer would be encouraged to seek advice than do so currently. Serious illness is uncommon in babies at home, and scores of 20 or more were rare, confirming that babies who achieve them need urgent assessment. ${ }^{4} 589$

The scores done between visits in study $B$ were higher than those done at the visits, suggesting that the mothers were using Baby Check appropriately when worried about their babies. Mothers often sought advice without using Baby Check (they were told not to rely on it), but those who did use it appear to have responded appropriately. Even allowing for unrecorded contacts, a score under 8 reassured most that medical advice was not required, while few ignored a score of 13 or more.

Many who said they would trust Baby Check qualified their answers. This is appropriateBaby Check is intended to assist rather than replace the mothers' judgment.

This study has shown that mothers welcome Baby Check, and with introduction and practice most should be able to use it effectively. If it were introduced as part of child care it would not increase, and might reduce, the numbers seeking medical advice. Baby Check should reassure mothers when attention is not required a well as prompting them to seek advice when this is necessary. Their willingness to use it long term will be affected by its presentation, and by whether it becomes an accepted and recommended part of baby care.

We thank the Baby Illness Research Project Appeal of the Foundation for the Study of Infants Deaths for financial support Foundation for the Study of Infants Deaths for financial support, the mothers and babies of Cambridge for their help, and Dr PH study.

Copies of the Baby Check score card and booklet can be Copies of the Baby Check
obtained from the authors.

1 Stanton AN, McWeeny PM, Jay AL, Irwin E, Oakley JR. Management of acute illness in infants before admission to hospital. BMF 1980;280:897-9.

2 McWeeny PM, Emery JL. Unexpected postneonatal death due to recognisable disease. Arch Dis Child 1975;50:191-6.

3 Stanton AN, Downham MAPS, Oakley JR, Emery JL, Knowelden $J$. Terminal symptoms in children dying suddenly and unexpectedly at home: preliminary report of the DHSS multicentre study of preliminary report of $B M \mathcal{F}$ 1978;ii:1249-51.

4 Morley CJ, Thornton AJ, Cole TJ, Hewson PH, Fowler MA Baby Check: a scoring system to grade the severity of acute Baby Check: a scoring system to grade the severity of acute
systemic illness in babies under 6 months old. Arch Dis Systemic illness in babies

5 Cole TJ, Morley CJ, Thornton AJ, Fowler MA, Hewson PH. A scoring system to quantify illness in babies under six months of age. Fournal of the Royal Statistical Society $A$ (in press).

6 Garraway WM, Akhtar AJ, Gore SM, Prescott RJ, Smith RG. Observer variation in the clinical assessment of stroke. Age Ageing 1979;5:233-40.

7 Thornton AJ, Morley CJ, Hewson PH, Cole TJ, Fowler MA, Tunnacliffe JM. Symptoms in 298 infants under 6 months old, seen at home. Arch Dis Child 1990;65:280-5.

8 Thornton AJ, Morley CJ, Cole TJ, Green SJ, Walker KA, Rennie JM. Field trials of the Baby Check score card in hospital. Arch Dis Child 1991;66:115-20.

9 Morley CJ, Thornton AJ, Green SJ, Cole TJ. Field trials of the Baby Check score card in general practice. Arch Dis Child 1991;66:111-4. 